\title{
EL SISTEMA DE AMPARO CONSTITUCIONAL VENEZOLANO
}

\section{Maria Fatima Pinho De Oliveira ${ }^{1}$}

\begin{abstract}
Resumen
La naturaleza del amparo se encuentra consagrada en la Constitución de la República Bolivariana de Venezuela como un mecanismo judicial; algunos autores consideran que el amparo es además un derecho humano que garantiza la existencia de los demás derechos humanos; así mismo es considerado una garantía pero actualmente va más allá, ya que es visto como un sistema de protección.El presente estudio está enmarcado en una línea de investigación de Derecho Constitucional, la metodología aplicada se encuentra basada en un estudio documentalbibliográfico, donde las principales fuentes de consulta fueron la Constitución de la República Bolivariana de Venezuela y la Ley Orgánica de Amparo sobre Derechos y Garantías Constitucionales. El estudio aborda algunos aspectos básicos sobre el sistema de Amparo Constitucional así como los principios doctrinarios que la rigen.
\end{abstract}

Palabras clave: Derecho, Amparo constitucional, Constitución.

\section{INTRODUCCIÓN}

En Venezuela, sólo se ha podido reconocer la existencia de un remedio expedito de control de derechos fundamentales, desde el año 1983, cuando una decisión de la Sala Político Administrativa de la entonces Corte Suprema de Justicia abrió paso, con la confianza y al mismo tiempo prudencia, al amparo constitucional.

Luego vino la Ley Orgánica de Amparo sobre Derechos y Garantías Constitucionales y la Constitución de 1999 con las grandes e importantes transformaciones que ello ha implicado, particularmente la creación de una Sala Constitucional encargada de, entre otras cosas, tratar de mantener -por así decirlo- un hilo jurisprudencial uniforme e materia de protección de derechos fundamentales.

La concepción del legislador de la Acción de Amparo como garantía de rango constitucional trae como consecuencia la definición e implementación de un conjunto de instrumentos que sirvan de defensa frente a las vulneraciones de los derechos constitucionales por parte de los órganos del Poder Público y también de los particulares.

\footnotetext{
${ }^{1}$ Doctorando en Derecho Constitucional, Profesora Agregado, adscrita al Departamento de Tecnología de Servicios de la Universidad Simón Bolívar, actualmente, Coordinadora de Ciencias Sociales y Administrativas del Decanato de Investigación. Email: mpinho@usb.ve
} 
La tutela de estos derechos provee al ciudadano el respeto mínimo que éste puede exigir y constituye el presupuesto básico sobre el que se debe edificar toda sociedad democrática.

La presente investigación se desarrolla bajo una perspectiva de tipo documental con diseño bibliográfico apoyado principalmente en libros, doctrina, leyes y jurisprudencia, donde se pretende dar a conocer algunos aspectos básicos sobre el sistema de Amparo Constitucional así como los principios doctrinarios que la rigen.

\section{BREVE HISTORIA DEL AMPARO CONSTITUCIONAL}

La Ley de Amparo, nació en 1988, con 27 años de atraso legislativo y 146 años de retraso histórico, respecto al Amparo Americano que había surgido en México, de la Constitución de Yucatán de 1842 y del Acta de Reformas, en 1847. (Mago, 1998, p.25).

En cuanto a los antecedentes venezolanos se tiene: el Decreto del Presidente de Venezuela, General José Antonio Páez, firmado también por el Presidente del Congreso de Venezuela José María Vargas, el 6 de agosto de 1830 (Mago, 1998, citado por Zerpa Díaz, 1984, p.29), cuando por primera vez, se asomaba el amparo:

... La libertad que tienen los venezolanos de reclamar sus derechos ante los depositarios de
la autoridad pública, con la moderación y respeto debidos, en ningún tiempo será impedida
ni limitada. Todos por el contrario deberán hallar un medio pronto y seguro, con arreglo a las
leyes, de las injurias y daños que sufrieren en sus personas, en sus propiedades, en su honor y
en su estimación... (Mago, 1998, p. 26, subrayado del autor).

También se puede apreciar algo similar en las Disposiciones Generales del Código Orgánico de Tribunales y Juzgados del 21 de febrero de 1850 (Mago, 1998, citado por Zerpa Díaz, 1984, p.30), donde se introduce la figura del Amparo con su efecto protector, suspensivo e inspirado en la justicia:

... Cuando cualquier funcionario público estuviere formando actuación criminal contra cualquier persona, o hubiere dictado decreto de prisión, el interesado y cualquiera a su nombre puede ocurrir a la Corte Superior respectiva por vía de Amparo y protección, y ésta mandando a suspender el procedimiento, pedirá la actuación y en vista, si lo encuentra de justicia, podrá levantar la providencia opresiva... (Mago, 1998, p. 26, subrayado del autor).

En la Constitución venezolana de 1947 (Constitución sancionada por la Asamblea Nacional Constituyente el 5 de julio de 1947, ejecutada por la Junta Revolucionaria del Gobierno de Rómulo Betancourt G.O No 194 Extraordinaria en fecha 30 de julio de 1947), incluyó, como lo relata Chavero, (2001)- un mecanismo de protección jurisdiccional del Derecho a la libertad personal denominado Habeas Corpus; se desarrolló en dos partes del texto constitucional, en el artículo 32 y en la Disposición Transitoria Decimoquinta. (Kiriakidis, 2012, p.121, 122).

Artículo 32. A toda persona detenida o presa con violación de las garantías establecidas en esta Constitución en resguardo de la libertad individual, le asiste el recurso de Habeas Corpus. Este recurso podrá ser ejercido por el interesado o por cualquiera otra persona en nombre de aquel, y será admisible cuando la ley no consagre contra la orden, acto o procedimiento que lo motive, ningún recurso judicial ordinario. 
La Ley determinará los Tribunales que conocerá y decidirán en forma breve y sumaria de las denuncias del caso, así como también las demás condiciones necesarios para el ejercicio de ese recurso.

DECIMAQUINTA. Mientras la Ley establece la competencia definitiva, se atribuye a los Tribunales de Primera Instancia en lo Penal el conocimiento del recurso de Habeas Corpus. Dentro de las 24 horas siguientes al recibo de las denuncias, dichos Tribunales requerirán de los funcionarios bajo custodia estuvieren detenidos, los motivos de la privación de la libertad; acto seguido, con vista a los resultados de la inquisición, ordenarán:

1. El sometimiento a juicio, si hubiere lugar a él;

2. Que se dicte la correspondiente resolución administrativa, si la detención obedeciere a causales de esta índole; 0

3. La inmediata libertad del detenido, si no estuviere dentro de los casos anteriores, sin perjuicio del procedimiento a que hubiere lugar, si los funcionarios ejecutivos incurrieren en responsabilidad penal por abuso de sus funciones.

El Habeas Corpus se establece entonces como un medio procesal, un recurso contra privaciones preventivas de libertad, siempre que las mismas no obedecieran a una orden judicial o administrativa expresa.

Como lo expresa el Autor Kiriakidis (2012), el Habeas Corpus no sólo se veía restringido por su objeto a un solo derecho fundamental, la libertad personal, sino que además su operatividad estaba limitada por dos requisitos concurrentes, (1) que esa privación no estuviera fundada en orden administrativa o judicial previa, y (2) que contra dicha orden no existiera recurso ordinario.

Luego el Amparo Constitucional era establecido definitivamente en el orden jurídico venezolano en el artículo 49 de la Constitución de 1961:

Artículo 49: Los tribunales ampararán a todos los habitantes de la República en el goce y ejercicio de los derechos y garantías que la Constitución establece, en conformidad con la Ley. (Constitución de la República de Venezuela, 1961)

La Ley Orgánica de Amparo (LOA), nace con cierto retraso a la necesidad de la sociedad Venezolana, ya que el constituyente de 1947 había dado el primer paso al aprobar el Habeas Corpus, que según el Autor Mago, (1998), no pudo desarrollarse en el país.

\section{OBJETO, FINALIDAD Y CAUSA DEL AMPARO}

La Constitución Nacional (1999), estableció en el artículo 27 la Acción de Amparo Constitucional, de cuyo texto se deduce que es el medio a través del cual se hacen efectivos los derechos, las restantes garantías, las facultades y las potestades que la Constitución consagra. En lo que se refiere a los derechos y garantías, son objeto de protección los que la Constitución consagra y menciona en forma expresa, o bien reconoce en forma genérica en su artículo 50. De acuerdo a esta concepción ampliada del amparo, desarrollada por la Ley Orgánica de Amparo sobre Derechos y Garantías Constitucionales, el objeto, la finalidad y la causa de esta institución pueden especificarse así: 
1. Objeto: Conforme al artículo 1 de la referida Ley el objeto viene a ser el amparo para el goce y ejercicio de los derechos, garantías y potestades constitucionales establecidas, o que sin figurar expresamente contempladas en ella, son inherentes a la persona humana (Artículo 50 Constitución Nacional, 1961).

2. Finalidad: Restablecimiento de la situación jurídica infringida, o la que más se asemeje a ella (artículo 1 LOA). Efecto restablecedor. Es necesario que la lesión o amenaza de lesión sea inmediata, posible y realizable por el imputado (Artículo 6, ordinal 2 LOA).

3. Causa: Violación o amenaza de violación de los derechos y garantías constitucionales derivados de:

a) Hechos, actos u omisiones (silencio rechazo) del Poder Público, Nacional, Estadal o Municipal (artículo2 LOA).

b) Contra normas legales que coliden con la Constitución, esto es, contra leyes y disposiciones legales o reglamentarias (artículo 3, LOA).

c) Actuaciones materiales, vías de hecho abstenciones u omisiones de la Administración Pública (artículo 5 LOA).

d) Para defenderse de resoluciones, sentencias o actos de los tribunales actuando fuera de la esfera de su competencia (artículo 4 LOA).

4. Presupuestos para el Ejercicio de la Acción.

Según Meléndez (1995), además de los requisitos de admisibilidad a que se refiere el artículo 6 de la LOA, la jurisprudencia de los tribunales ha llegado a exigir como presupuesto de procedencia para el ejercicio de la acción de amparo, que se llenen los siguientes extremos:

1. Que exista violación directa o desconocimiento de normas o garantías constitucionales o legales, cuando la garantía o derecho violado o amenazado de violación se encuentre desarrollado y regulado por una ley, es decir que se trate de un derecho constitucionalizado.

2. Carácter extraordinario del amparo, es decir, que se admite, aún existiendo otras vías de actuación cuando el agotamiento de las mismas podría transformar el daño en irreparable.

\section{NORMATIVAS LEGALES Y PRINCIPIOS DOCTRINALES QUE DETERMINAN EL EJERCICIO DE LA ACCIÓN DE AMPARO}

Las proposiciones contenidas en el presente estudio se fundamentan legalmente en los siguientes documentos: Constituciones de República de 1961 y 1999 y además la Ley Orgánica de Amparo sobre Derechos y Garantías Constitucionales.

A continuación se describen los aspectos tomados de cada uno de los documentos mencionados. 
La acción de amparo se basó en el Artículo 49 de la Constitución Nacional del año 1961 inicialmente y establecía lo siguiente:

Los tribunales ampararán a todo habitante de la Republica en el goce y ejercicio de los derechos y garantías que la Constitución establece, en conformidad con la Ley.

El procedimiento será breve y sumario, y el Juez competente tendrá potestad para restablecer inmediatamente la situación jurídica infringida.

El precepto dogmático de la Constitución de 1961 contenido en este artículo 49, (actualmente artículo 27 de la Constitución de 1999) sirve de fuente inmediata para fundamentar el amparo constitucional establecido en el Artículo 1 de la Ley Orgánica. En primer lugar, el legislador establece una diferenciación entre la regulación del amparo en general y la garantía de la libertad personal o individual que viene a ser el hábeas corpus.

En el artículo 2 de la Ley Orgánica, también fundamentado en el Titulo I de la citada Constitución, relativo a las Disposiciones Fundamentales, se mencionan las circunstancias en las cuales procede la acción de amparo. Además de la procedencia, habría que destacar, en este artículo, el concepto de "amenaza válida". El legislador dice que "... se tendrá como amenaza válida para determinar la procedencia de la acción de amparo aquella que es inminente...". Los artículos 3, 4 y 5 también regulan casos en los cuales procede la acción de amparo. Se desprende de la lectura de estos artículos que el legislador no fue cuidadoso en el uso del lenguaje. En estos, así como en otros artículos, se utilizan adjetivos calificativos que no vienen calificar menor situaciones perfectamente descritas. Al decir el legislador "Breve, sumaria y efectiva", esta última palabra parece estar de más porque el juez al emitir un pronunciamiento está realizando un acto real, verdadero y que, como es obvio, se opone a lo quimérico o dudoso.

Pues bien, en el caso de las acciones de amparo ejercidas contra algún acto judicial, el legislador estableció un régimen de excepción los principios rectores que rigen la competencia en el amparo común o ejercido en forma autónoma, intentado contra cualquier acto, hecho u omisión emanado del resto de los órganos del Poder Público o de algún particular. Estas reglas básicas se encuentran establecidas en los Artículos 7 y 8 de la Ley Orgánica de Amparo sobre Derechos y Garantías Constitucionales.

En esta ley, vigente hasta los momentos, se recogen los criterios rectores para residenciar los amparos en los distintos tribunales competentes los cuales han sido denominados comúnmente por la doctrina como el criterio material y el criterio orgánico. Someramente, estos criterios consisten en lo siguiente:

1. El criterio material o por afinidad, es el consagrado en el artículo 7 de la Ley Orgánica de Amparo, y consiste en atribuir la competencia de las acciones de amparo a los tribunales que se encuentren más familiarizados por su competencia ordinaria con los derechos o garantías constitucionales cuya violación denunciada señala expresamente el artículo mencionado:

Artículo 7. Son competentes para conocer de la acción de amparo, los tribunales de Primera Instancia que lo sean en la materia afín con la naturaleza del derecho o garantía violados y/o amenazados de violación en la jurisdicción correspondiente al lugar donde ocurrieren el hecho, acto u omisión que motivaren la solicitud de amparo. 
En caso de duda se observarán, en lo pertinente, las normas sobre competencia en razón de la materia.

Si un Juez se considerare incompetente, remitirá las actuaciones inmediatamente a las que tenga competencia.

Del amparo de la libertad y seguridad personales conocerán los Tribunales de Primera Instancia en lo Penal, conforme al procedimiento establecido en esta ley.

2. El otro criterio rector que destaca la Ley Orgánica de Amparo sobre derechos y Granitas Constitucionales, es el denominado usualmente orgánico, y está consagrado en el artículo 8, que textualmente dispone:

Artículo 8. La Corte Suprema conocerá, en única instancia y mediante aplicación de los lapsos y formalidades previstos en la Ley, en la Sala de Competencia afín con el derecho o la garantía constitucionales violados o amenazados de violación, de la acción de amparo contra el hecho, acto u omisión emanados del Presidente de la República, de los Ministros, del Consejo Supremo Electoral y demás organismos electorales del país, del Fiscal General de la República, del Procurador General de la República o del Contralor General de la República.

¿Qué sucede con el régimen procesal de la Ley? La acción de amparo es un valioso instrumento procesal que puede ser interpuesto, ante el juez competente, por cualquier persona natural o jurídica directamente o por intermedio de representante. La diferencia fundamental con otros procedimientos es que en el amparo el régimen se nos presenta más expedito, estando los trámites procésales desprovistos de las sacrosantas formalidades exigidas para las vías judiciales ordinarias.

A través de este procedimiento informal lo que se busca es el restablecimiento inmediato de los derechos y garantías violados.

\section{PRINCIPIOS DOCTRINALES}

El precepto del Artículo 27 de la Constitución de 1999 es uno de los aciertos más destacados de esa Constitución, ya que en una redacción breve y precisa se establecen los principios fundamentales del Amparo, los cuales responden a los siguientes aspectos: ¿Cuál es su naturaleza?, ¿Tiene plena vigencia?, ¿Quién solicita?, ¿Ante cuál tribunal se ejerce?, ¿Contra qué actos procede?, ¿Cuál es el procedimiento? Y finalmente ¿Cuándo Procede?.

\section{Principio de la Protección Jurisdiccional del Amparo}

Un concepto tradicional identifica las garantías constitucionales con los derechos de la persona humana consagrados en las disposiciones constitucionales, de acuerdo con la corriente clásica que se origina en la Revolución Francesa de 1789, según la cual los derechos naturales se transformaban en garantías, en cuanto se consignaran en las disposiciones de las Cartas Fundamentales.

Sin embargo, después de una lenta evolución, tanto la doctrina como la legislación, abandonaron paulatinamente esta significación, si se toma como ejemplo la elaboración del concepto de las "garantías de derecho público", entre las cuales se incluían las de carácter jurídico, como instrumentos, inclusive jurisdiccionales, para la tutela de los derechos fundamentales; y en segundo término la posterior explicación de la doctrina con vol. 08, no. 04, Número Especial. 2015.pp. 2344-2364 
respecto a las garantías preventivas y represivas, al estimar que las primeras tienden a evitar las violaciones de las disposiciones constitucionales, mientras que las segundas sirven de freno a la arbitrariedad del Estado.

Es importante en esta materia la aportación de Hans Kelsen (s/f), al aplicar su concepto de la estructura lógica de la norma jurídica al derecho constitucional y estimar que, así como las normas de otras ramas del ordenamiento jurídico cuentan con instrumentos procesales para sancionar el incumplimiento de su mandato, era indispensable que se determinara el procedimiento y el órgano competente para sancionar las violaciones de los preceptos constitucionales.

Según la evolución expuesta, son numerosos los autores que consideran que las verdaderas garantías de la Constitución y específicamente, de los derechos fundamentales, consisten precisamente en su protección jurisdiccional, para lo cual han desarrollado una corriente doctrinal muy elaborada sobre lo que se denomina como una frase feliz de Mauro Cappelletti: "Jurisdicción Constitucional de la Sociedad”. (Kelsen, s/f)

En consecuencia, se debe considerar que en la doctrina, y aún en el texto constitucional, es preciso distinguir entre los derechos consignados en la Constitución y garantías de los mismos, que no son otra cosa que los medios procesales por medio de los cuales es posible su protección y eficacia, y es este sentido el adoptado por la mayoría de la doctrina nacional sobre el Amparo, consagrado en el Artículo 27 de la Constitución Bolivariana de la República de Venezuela (1999).

\section{Principios Subjetivos del Amparo}

En relación con el beneficio de la acción de Amparo, puede apreciarse que si bien existe uniformidad en la doctrina al decir que lo es "toda persona", sin distinción entre naturales y extranjeros, según el concepto territorial del vocablo, no acontece lo mismo cuando se observa que tal condición la ostenten, no sólo las personas naturales sino también las jurídicas.

1. Según una posición, la denominación "persona" se refiere a la persona física, pues la Constitución sólo garantiza los derechos individuales, sociales, económicos y políticos, esencial y fundamentalmente a la persona, al ser humano.

2. Hay quienes razonan, sin embargo, interpretando en toda su amplitud la expresión "toda persona", que la acción de Amparo puede entenderse como referido no sólo a las personas naturales, sino también a las personas jurídicas, pues los derechos que la Constitución establece no sólo corresponden a aquellas, sino que muchos también se garantizan respecto de las jurídicas.

Se cree que esta posición debe admitirse, puesto que la titularidad de los derechos fundamentales a favor de las personas jurídicas es lógica y realmente factible. 
En cuanto al tribunal que ha de conocer delaacción de Amparo, al efecto el Artículo 27 de la Constitución de 1999 estableció un deber a los tribunales del país, cuando señala que tales órganos "ampararán a toda persona". Sin embargo, la referencia que hace el mismo artículo a un juez competente, que no se determina de modo expreso, ha igualmente propiciado una interesante polémica.

1. Según una de las posiciones doctrinales sostenida a este respecto, la Constitución del 1999 ofrece una competencia constitucional a todos los Tribunales, para conocer de pretensiones con fundamento en la acción de Amparo.

2. Otra posición establece que esta atribución concedida por el Artículo 27 de la Constitución de 1999 no es específica, ya que esta expresión de "Tribunales" esta usada como sinónimo de "Poder Judicial". En consecuencia no existe ningún tribunal que tenga atribución para conocer la acción de Amparo.

3. La posición que comparte la autora de la presente investigación es que, si bien cualquier tribunal de la República tiene jurisdicción para conocer del Amparo, éstos se regirán por las disposiciones generales sobre competencia, en razón de la materia; esto es, la competencia corresponderá a los jueces que tengan asignada dentro de su competencia ordinaria la materia sobre la cual versa el derecho fundamental cuya violación se alega.

\section{Principio Objetivo del Amparo}

El objetivo de Amparo es la tutela de unos determinados derechos: los derechos constitucionales. (Hoyos, 1989).

La doctrina no delimita del mismo modo el ámbito de los derechos fundamentales protegidos, ni de los actos frente a los que se efectúa la tutela, ni de los sujetos de quienes estos últimos provienen.

La doctrina se divide, con respecto a los derechos fundamentales en cuanto a los siguientes aspectos:

1. Hay quienes sostienen que la esfera tutelada es sólo la de los derechos individuales, con lo cual se excluye todo el campo de los demás derechos constitucionales sociales, económicos y políticos, ya que se afirma que están protegidos respectivamente por legislaciones especiales.

2. Frente a éstos hay otro sector que considera que el Amparo no sólo tutela los derechos individuales, como eran entendidos tradicionalmente, sino que puede darse en relación con todos los derechos fundamentales, enunciados o no en la Constitución, pues si ésta es una "Carta de Derechos", cuales quiera de ellos es susceptible de protección por el Amparo.

En efecto, la funcionalidad del Instituto del Amparo no se agota en la estimable tutela de la esfera individual de la persona humana, sino que también se aplica a los derechos sociales, económicos y políticos, y que pueden darse a este respecto auténticas situaciones jurídicas subjetivas constitucionalmente protegidas, que 
permiten imputar determinadas pretensiones jurídicas a los titulares de derechos en cuanto a las mismas y no es, por tanto, mera expresión retórica de un programa legislativo que se inserta al texto constitucional, sin eficacia inmediata alguna.

\section{Principio de Urgencia de la acción de Amparo}

El Artículo 27 de la Constitución de 1999, se limita a señalar que "... el procedimiento será oral, publico, breve, gratuito y no sujeto a formalidad ...", delegando así en el legislador la facultad de dictar una ley en la cual se establezca en forma detallada el procedimiento correspondiente.(Hoyos, 1989).

Ante esta situación surgió una controversia, en la cual alegaban algunos que la ausencia de determinación del procedimiento impedía la plena vigencia del Amparo; por ser evidente la intención del constituyente de limitar su alcance al caso expresamente previsto en ella, dado que constituye una norma procedimental de carácter excepcional, respecto de la cual no cabe aplicación analógica, pues ésta sólo es lícita en caso de silencio de la ley, y no hay tal cuando el Legislador explícita o implícitamente a manifestado su voluntad. En este modo, en los casos de lesión de los referidos derechos fundamentales, habría que recurrir para el restablecimiento de la situación jurídica infringida al procedimiento ordinario.

\section{NATURALEZA Y CARACTERÍSTICAS DEL PROCEDIMIENTO DE AMPARO}

Puede decirse que el amparo, “... es una forma diferenciada de tutela jurisdiccional de los derechos y garantías constitucionales, cuyo propósito es garantizar a su titular, frente a la violación o amenaza de violación de uno de tales derechos y garantías, la continuidad de su goce y de su ejercicio, a través del otorgamiento de un remedio específico que a objeto de restablecer la situación jurídica infringida, evite la materialización y permanencia del hecho lesivo y de sus efectos". (Voto Salvado suscrito por el Magistrado Moises Troconis en la Sentencia de la Sala Constitucional del Tribunal Supremo de Justicia No 95 de fecha 13 de marzo de 2000, citado de Kiriakidis, 2012).

En el procedimiento de amparo, el juez instruye actuaciones lesivas de derechos fundamentales pero, en ningún caso, puede revisar la aplicación o interpretación del derecho ordinario por parte de la administración o los órganos judiciales, a menos que ella se derive una infracción de la Constitución. No se trata de una nueva instancia judicial o administrativa, ni de la sustitución de los medios ordinarios para la tutela de los derechos e intereses, se trata de la reafirmación de los valores constitucionales, en la cual el juez conoce del amparo puede pronunciarse acerca del contenido o aplicación de las normas constitucionales que desarrollan los derechos fundamentales, revisar la interpretación que de estos han revisado los distintos operadores jurídicos, o establecer si los hechos de los que se deducen las violaciones constitucionales constituyen una violación de la Constitución. 
Así, cuando la infracción a una ley es, a su vez, una transgresión a la Constitución, procede al amparo, sin que sea necesario distinguir como hacia la jurisprudencia pre-constitucional, inmediata de la Constitución. Es decir, para que el amparo proceda, es necesario que exista una infracción por acción u omisión a una norma constitucional, aún cuando ésta sea realizada mediante desconocimiento, mala praxis, o errada interpretación de normas legales o sub-legales, siempre que se enerve el goce y ejercicio pleno de un derecho constitucional.

La Sala ha dicho que el juez constitucional debe interpretar en todo caso, si bien de manera casuística, el núcleo esencial de tales derechos, es decir, abstraer su contenido mínimo según el cual el derecho hace imprescindible para la dignidad, igualdad y libertad humana. Si la norma constitucional resulta directamente aplicable a la solución del conflicto, o lo es una norma de rango inferior en cuyo contenido esté reflejado o se encuentra implícito en un derecho humano, entonces, el acto, actuación u omisión que le desconoció es posible, en principio, de procedimiento de la tutela en vía de amparo.

En la sentencia de Luis Alberto Baca, № 00-529 de fecha 28-07-00, la Sala expresó que es de la naturaleza del Amparo la condición de la reparación inmediata de la situación lesiva de derechos constitucionales, hasta al punto de que la acción es inadmisible cuando la amenaza no sea inmediata, o cuando la lesión sea irreparable, por no ser posible el restablecimiento de la situación jurídica infringida, según numerales 2 y 3 del artículo 6 de la Ley Orgánica de Amparo sobre Derechos y Garantías Constitucionales.

Ya había declarado la Sala Constitucional, con ponencia de Delgado Ocando, en sentencia No01-2636 de fecha 19-05-00 que la inmediatez una de las claves del amparo, por ello, cuando se puede acudir a la vías procesales ordinarias, sin que la lesión a la situación se haga irreparable, es a estas vía a las que hay que acudir. Éste es el criterio decisivo en la materia. Si la tramitación de la apelación, o el recurso, o el juicio, por ejemplo, no van a agravar la lesión a la situación jurídica, es el trámite o el medio procesal ordinario la vía para reparar la lesión y no la acción de amparo.

En sentencias posteriores, la Sala ha procesado que la acción opera bajo las siguientes condiciones:

a. A una vez que la vía judicial haya sido instada y que los medios recesivos hayan sido agotados, siempre y cuando la invocación formal del derecho fundamental presuntamente vulnerado, en la vía o a través del medio correspondiente, no haya sido satisfecha; o

b. Ante la evidencia de que el uso de los medios judiciales ordinarios, en el caso concreto y en virtud de la urgencia de la restitución, no hará satisfacción a la pretensión deducida.

El primer supuesto apunta a la comprensión de que el ejercicio de la tutela constitucional por parte de todos los jueces de la República, a través de cualquiera de los canales procesales dispuestos por el ordenamiento jurídico, es una características inmanente al sistema judicial venezolano, por lo que, ante la interposición de una acción, de amparo constitucional, los tribunales deberán revisar si fue agotada la vía ordinaria o fueron ejercidos los recursos y, de no constar tales circunstancias, la consecuencia será la inadmisión de la acción, pues el carácter tuitivo que la Constitución atribuye a las vía o medios procesales ordinarios les imprime la potestad de conservar o restablecer el goce de los derechos fundamentales, por lo que su agotamiento es un presupuesto procesal a la admisibilidad de la acción del amparo. 
El segundo supuesto (b), relativo a que la acción de amparo puede proponerse inmediatamente, esto es, sin que hayan sido agotados los medios o recursos adjetivos disponibles, el mismo procede cuando se desprenda de las circunstancia fácticas o jurídicas que rodean la pretensión, que el uso de los medios procesales ordinarios resulta insuficiente al restablecimiento del disfrute del bien jurídico lesionado.

También ha tenido que precisar la Sala que la infracción del derecho a la defensa o al debido proceso, por actuación u omisión judicial, no se produce con toda infracción de reglas procesales. Solo cuando la infracción impida a una parte ejercer su defensa, enervándole las oportunidades para alegar y probar, acercándole la contradicción y el control de las pruebas de su contraparte, o impidiéndole conocer lo que se le imputa o se pretende de él, o negándole el uso de los medios que la ley adjetiva establece un desarrollo de la garantía jurisdiccional y del derecho al debido proceso, será cuando ocurra la infracción constitucional en materia de la acción de amparo; por lo que quien demande en amparo contra una decisión judicial deberá alegar como y de manera la infracción procesal denunciada le impide o menoscaba el ejercicio de sus derechos constitucionales a la defensa, al debido proceso o a la tutela judicial efectiva, indicando, en principio expresamente, la actividad procesal concreta a la que tenía o tendría derecho en ejercicio de sus derechos constitucionales, que le ha sido impedida por la violación procesal o de que manera la infracción cometida por el juez le menoscaba el ejercicio de algún otro derecho constitucional.

Desde otro punto de vista, la Sala señaló en una de sus primeras decisiones (sentencia $\mathrm{N}^{\circ} 7$ del 01-0200) que el estado venezolano es, conforme a la vigente Constitución (artículo 257) un Estado de Derecho y de Justicia, que patentiza que las formas quedan subordinadas a las cuestiones de fondo.

Esto significa que quienes piden la aplicación de normas constitucionales no necesitan ceñirse a formas estrictas, tal como lo denota el artículo 26 de la Constitución. Por lo tanto, lo importante para quien accione en amparo es que su petición sea inteligible y pueda precisarse que quiere, es decir, su pretensión.

En consecuencia el petitorio de un amparo puede no ser vinculante para el tribunal que conoce de la acción, ya que, tal como se desprende de los artículos 3 y 334 de la Constitución, existe el interés constitucional de que quienes pidan la intervención del poder judicial en el orden constitucional reciban efectivamente los beneficios constitucionales, sin decisiones o minimizaciones causadas por carencias o errores en el objeto de las peticiones como también sin extralimitaciones provenientes del objeto de sus pretensiones, ya que, de ser así, el juez constitucional estaría obrando contra el estado de Derecho y Justicia a que refiere la Constitución. 


\section{PRINCIPIOS DEL PROCESO DEL AMPARO CONSTITUCIONAL}

Estos principios elementales del proceso de amparo constitucional son de vital importancia, debido a que de producirse una reforma legislativa de la Ley Orgánica de Amparo Sobre Derechos y Garantías Constitucionales, estos principios son los que deberían servir de base para enfocar las nuevas modificaciones.

\section{Principio de sumariedad o brevedad en el amparo}

En la Ley Orgánica de Amparo Sobre Derechos y Garantías Constitucionales se establece que es posible la interposición de la acción por vía telegráfica; se señala que el lapso para presentar el informe a que se refiere el artículo 23 de dicha Ley es de cuarenta y ocho (48) horas; la audiencia constitucional debe celebrarse dentro de las noventa y seis (96) horas siguientes a la presentación del informe; y la decisión debe producirse al día siguiente.

De igual forma y para proteger el carácter sumario de la acción, se prohibió la recusación de los jueces, no se consagró un lapso probatorio, dejando a salvo la posibilidad de que el juez considere procedente a ordenar la evacuación de las pruebas que juzgue conveniente y siempre que no constituya un prejuicio irreparable para el actor. En general, de conformidad con éste principio de celeridad procesal, queda negada cualquier otra incidencia que pretenda dilatar la continuidad del proceso.

Adicionalmente el artículo 27 de la Constitución de la República Bolivariana de Venezuela (1999) ratifica, incluso ahora con mayor énfasis, el carácter breve y urgente de este procedimiento.

Por tanto, en el procedimiento de amparo, plasmado en la sentencia del $1^{\circ}$ de febrero de 2000 , refleja con mayor intensidad el principio de la brevedad del proceso de amparo constitucional.

En efecto, en dicho procedimiento se ratifica este principio al disponer que una vez admitida la acción de amparo constitucional deberá convocarse de una vez y dentro de las noventa y seis (96) horas siguientes a la audiencia constitucional oral y pública, eliminando el lapso de cuarenta y ocho (48) horas previsto en el artículo 23 de la Ley Orgánica de Amparo para que el presunto agraviante presentara el informe correspondiente.

También se dispone en el procedimiento, como forma de garantizar la celeridad procesal, que la decisión de la causa podrá efectuarse en el mismo momento en que termine la audiencia constitucional a que se refiera el artículo 26 de la Ley Orgánica de Amparo. De ésta forma, el tribunal competente podrá dictar el dispositivo del fallo, reservándose la publicación definitiva de la decisión para dentro de los cinco (5) días siguientes a la audiencia.

No se puede dejar de mencionar una decisión dictada por la Sala Constitucional, en fecha 31-05-00, caso: seguro Los Andes C.A., donde se precisó el lapso a los tres (3) días a que se refiere el artículo 35 de la Ley 
Orgánica de Amparo debe computarse por días de despacho del tribunal respectivo, y no por días consecutivos, como parece indicar el artículo 13 ejusdem. Se cita a continuación lo que señalo la Sala:

En relación con los lapsos para interponer el recurso de apelación en amparo, esta Sala Constitucional considera que admitir el lapso de apelación previsto en el artículo 35 de la Ley Orgánica de Amparo Sobre Derechos y Garantías Constitucionales debe computarse por días continuos, incluyendo sábado, domingo y feriados, sería atentatorio contra el derecho a la defensa, principio cardinal del sistema procesal, pues el ejercicio del recurso de apelación se vería limitado de hecho, incluso cercenado, bien por la llegada del fin de semana, o alguna fiesta patria.

Por otra parte, una correcta interpretación del artículo 35 de la Ley Orgánica de Amparo Sobre Derechos y Garantías Constitucionales, no puede anteponer el principio de celeridad al derecho a la defensa, en virtud de que los principios procesales están subordinados a la garantía del debido proceso.

Adicionalmente, resulta incierto pretender que la celeridad procesal del amparo se vea lesionada por la interposición de recurso alguno, pues el mismo artículo 35 de la Ley aplicable establece que la apelación en materia de amparo solo se admite en solo efecto, esto es, el devolutivo, más no en el suspensivo, lo que permite concluir a la Sala Constitucional que el valor tuitivo de la sentencia de primera instancia, no ve menoscabada su eficacia por la interposición de la apelación.

Bajo éste orden de ideas, considera la Sala Constitucional que el Lapso de tres (3) días para interponer el recurso de apelación en amparo, previsto en el artículo 35 de la Ley Orgánica de Amparo Sobre Derechos y Garantías Constitucionales, debe ser computados por días calendarios consecutivos, excepto los sábados, los domingos, y el jueves y el viernes santos, los declarados días de fiestas por la Ley de Fiestas Nacionales y los declarados no laborables por las otras leyes, y así se declara, reiterando con carácter vinculante lo ya expresado en el fallo del $1^{\circ}$ de febrero de 2000 (caso: José Armando Mejía)"

\section{Principio de bilateralidad del proceso de amparo}

No puede existir ningún acto estatal que se dicte con prescindencia de la participación de los afectados, ni un Estado que pretenda denominarse de Derecho puede permitirlo.

Con la Constitución de 1999 ha surgido, para algunos, la duda sobre el renacimiento o revitalización del llamado "amparo inmediato" consagrado en el artículo 22 de la Ley Orgánica de Amparo Sobre Derechos y Garantías Constitucionales, ello en virtud de que el artículo 27 de la Constitución vuelve a repetir la frase que se señala que "... la autoridad judicial competente tendrá potestad para restablecer inmediatamente la situación jurídica infringida o la situación que más se asemeja a ella...”. Sin embargo, si es el criterio que esta frase no habilita al legislador o al juez a entender que se pueda emitir una decisión de amparo constitucional definitiva, sin garantizar el principio de bilateralidad o el derecho a la defensa del presunto agraviante.

Por las razones siguientes: 
1. En primer lugar, la misma frase fue contenida en el artículo 27 de la Constitución se encontraba presente en el artículo 49 de la Constitución de 1961, y ello no fue obstáculo para que el Máximo Tribunal entendiera de que el artículo 22 de la Ley Orgánica de Amparo Sobre Derechos y Garantías Constitucionales era inconstitucional, por vulnerar el derecho a la defensa, el emitir un mandamiento de amparo constitucional sin haber convocado al proceso al sujeto agraviante. De modo que, en nada debería afectar el nuevo artículo constitucional que regula la acción de amparo constitucional, pues conserva prácticamente la misma redacción. La frase debe ser emitida como una forma para habilitar del poder cautelar del juez de amparo, otorgándole competencia para disponer las medidas provisionales que considere necesario para garantizar que la parte que parece que va a obtener la razón, no sufra un daño significativo durante el proceso necesario para obtenerla.

2. El segundo argumento para rechazar el renacimiento del amparo inmediato se refiere a la forma como debe interpretarse el texto constitucional. Las normas constitucionales no pueden ser interpretadas de forma aislada, sino en conjunto o vinculadas con otras normas del mismo texto constitucional. De ésta forma, el artículo 27 de la Constitución debe ser interpretado junto con el artículo 49 de la misma Constitución, el cual consagra y desarrolla ampliamente el derecho a la defensa y al debido proceso.

Adicionalmente, hay que señalar que la Sala Constitucional del Tribunal Supremo de Justicia entendió, acertadamente, que no ha resurgido la figura del amparo inmediato, pues en la decisión dictada el $1^{\circ}$ de febrero de 2000, mediante la cual se rediseñó el procedimiento de amparo constitucional, no se hace mención alguna a la posibilidad de decretar de acciones de amparo constitucional inaudita alteran parte, por lo que entendemos que siguen vigente la posición jurisprudencial que considera inconstitucional el artículo 22 de la Ley Orgánica de Amparo.

\section{Principio del carácter de orden público del proceso de amparo}

Éste carácter de orden público en el proceso de amparo puede llegar, incluso, a que el juez constitucional admita una acción de amparo constitucional, a pesar de que la lesión constitucional no ha sido consentida por el agraviante, sea expresamente o por haber dejado transcurrir más de seis (6) meses desde el momento en que surgió ésta lesión. Ello conforma a lo dispuesto en el numeral 4 del artículo 6 de la Ley Orgánica de Amparo.

El artículo 17 de la Ley Orgánica de Amparo Sobre Derechos y Garantías Constitucionales dispone que el juez constitucional puede ordenar, siempre que no signifique un perjuicio irreparable para el actor, la evacuación de las pruebas que juzgue necesaria para el esclarecimiento de los hechos. En este caso, y según lo establece la sentencia dictada por la Sal Constitucional el $1^{\circ}$ de febrero de 2000, el juez podrá diferir la audiencia 
constitucional por un lapso no mayor de cuarenta y ocho (48) horas, para ser efectiva la evacuación de las pruebas ordenadas.

La mencionada decisión preciso lo siguiente:

El estado venezolano es, conforme a la vigente Constitución, un Estado de derecho y de justicia, lo que se patentiza en que las formas quedan subordinadas a las cuestiones de fondo, y no al revés /artículo 257 de la Constitución).

Esto significa que en materia de cumplimiento de las normas constitucionales, quienes piden su aplicación no necesitan ceñirse a formas escritas y a su ritualismo inútil, tal como lo denota el artículo 26 de la Constitución de la República Bolivariana de Venezuela. Por lo tanto, lo importante para quien accione un amparo es que su petición sea intangible y pueda precisarse que o sobre quién. Tan es así, que el amparo puede interponerse verbalmente, en este caso el alegato debe constar en acta, donde solo se referirá a los hechos esenciales.

Estrechamente relacionado con el carácter de orden público del proceso de amparo se encuentra la controversia jurisprudencial que se ha sostenido en relación con la posibilidad de denunciar la violación de los derechos fundamentales en la audiencia constitucional, a pesar de que ello no se haya realizado en el escrito de solicitud de amparo.

\section{Principio de igualdad procesal}

Este principio puede resumirse en la máxima de no crear preferencias ilegítimas. Es decir, todas las partes inmiscuidas en un proceso de amparo constitucional deben tener las mismas posibilidades y oportunidades para presentar y probar sus alegatos. Pues bien, la Ley Orgánica de Amparo Sobre Derechos y Garantías Constitucionales establece en su artículo 21 que “... los jueces deberán mantener la absoluta igualdad entre las partes y cuando el agraviante sea una autoridad pública quedarán excluidos del procedimientos los privilegios procesales ...".

El fallo de la Sala Constitucional de fecha $1^{\circ}$ de febrero de 2000 también se deja claramente establecido que la forma en cómo se desarrollaran las audiencias y la evacuación de las pruebas, si fueran necesarias, las dictará en las audiencias, el Tribunal que conozca del amparo, siempre manteniendo la igualdad entre las partes y el derecho de defensa.

\section{Principio de gratuidad del proceso de amparo}

Principio que tiene como finalidad permitir el libre acceso a los tribunales para lograr restablecer cualquier situación jurídica infringida de carácter constitucional. La Ley Orgánica de Amparo Sobre Derechos y 
Garantías Constitucionales establece en su artículo 16 que la “... acción de amparo es gratuita por excelencia. Para su tramitación no se empleará papel sellado ni estampillas...”

Además actualmente la interpretación judicial imperantes de los artículos 26 y 254 de la Constitución indica que la justicia es gratuita no solo para los procesos de amparo constitucional, también para el resto de los procedimientos judiciales que se ventilan ante el Poder Judicial.

\section{Principio de la doble instancia en los procesos de amparo}

Aún cuando se trata de un proceso breve y sumario, tal como se ha indicado, el legislador consagró el principio de la doble instancia obligatoria en estos procesos, quizás con la finalidad de buscar mayor ponderación en la ulterior decisión, para lo cual le concedió el juez de segunda instancia un lapso de treinta (30) días, pero dejo claro que la apelación -o en todo caso la consulta- se escuche en un solo efecto. Así, el artículo 35 de la Ley Orgánica de Amparo Sobre Derechos y Garantías Constitucionales destaca que:

Contra la decisión dictada en primera instancia sobre la solicitud de amparo oirá apelación en un solo efecto. Si transcurrido tres (3) días de dictado el fallo, las partes, el Ministerio Público o los Procuradores no interpusieron apelación, el fallo será consultado con el tribunal superior respectivo, al cual se le remitirá inmediatamente copia certificada de lo conducente. Este Tribunal decidirá en un lapso no mayor de treinta (30) días.

Este principio de doble instancia tiene sus excepciones, la primera de ella se encuentra consagrada en el artículo 8 de la Ley Orgánica de Amparo Sobre Derechos y Garantías Constitucionales, el cual establece un fuero especial, ahora a favor únicamente de la Sala Constitucional del Tribunal Supremo de Justicia, según lo dispuesto en la decisión dictada por esa misma Sala en fecha 20 de enero de 2000, en la cual se atribuye el conocimiento de todas las acciones que aún eran conocidas en primera y única instancia o en apelación de consulta por la Corte Suprema de Justicia (Hoy Tribunal Supremo de Justicia).

Hay que señalar que existe una segunda situación que pudiera considerarse como una excepción al principio de la doble instancia. La autora de la investigación se refiere a la competencia extraordinaria que tiene la Sala Constitucional (ordinal $10^{\circ}$ del artículo 336 de la Constitución), mediante la cual es posible que esta Sala asuma el conocimiento de una sentencia.

\section{Principio de escritura y oralidad}

Para dar aún más celeridad al proceso y para buscar mayor inmediación entre los hechos presuntamente determinantes de una vulneración constitucional y el juez competente, la Ley Orgánica de Amparo Sobre Derechos y Garantías Constitucionales ensayó una mezcla del sistema escrito con el oral, pues si bien la solicitud, los informes y las conclusiones debían ser presentadas por escrito, caso que se consagró en artículo 26, también presenta una audiencia oral y pública donde se encuentran los argumentos y pruebas que se debaten en el proceso. 


\section{Principio de la informalidad en la tramitación del amparo constitucional}

Otro de los principios elementales que caracterizan la institución de amparo constitucional, y actualmente pareciera que a toda la administración de justicia, es el principio de la informalidad, el cual se opone a las rigurosas concepciones del derecho formalistas que impiden un análisis de fondo sobre el punto realmente debatido. Pues bien, la acción de amparo, por ser breve y sumaria, se sirve de la informalidad para garantizar esta celeridad y para evitar que interpretaciones exageradas del derecho adjetivo avalen una vulneración de derechos fundamentales.

La informalidad rige además la forma como debe llevarse la audiencia constitucional, donde el juez puede otorgarle a las partes el tiempo necesario para que expongan libremente sus argumentos, respetando siempre el principio de igualdad de las partes en el proceso.

\section{GENERALIDADES DEL PROCEDIMIENTO DE LA ACCIÓN DE AMPARO DE LA SENTENCIA NÚMERO 7 DEL 01 DE FEBRERO DE 2000.}

La sentencia $\mathrm{N}^{\circ} 7$ del 01-02-2000, apremiada por la vigencia inmediata del artículo 27 de la Constitución que exige para la acción de amparo un procedimiento oral, público, breve, gratuito y no sujeto a formalidades y apoyada en el artículo 49 que consagra el derecho al debido proceso y en el artículo 335 ejusdem, que le otorga la facultad de establecer la interpretación y alcance de las normas y principios constitucionales en forma vinculante, es sin lugar a dudas, la ley vigente a efectos del trámite de la acción de amparo y de manera similar a como, en su momento, la sentencia "RAP" fue la ley especial de amparo antes de que esta fuese dictada.

Con respecto al segundo estableció que:

1. Se inicia conforme lo disponen los artículos 16 y 18 de la Ley Orgánica de Amparo Sobre los Derechos y Garantías Constitucionales pero que, adicionalmente a los registros fijados por éste último, el accionante deberá promover sus pruebas (so pena de preclusión de la oportunidad) y además deberá producir todos los medios escritos, audiovisuales o gráficos de que disponga.

2. Una vez admitida la acción se notificará al Ministerio Público y al presunto agraviante para que comparezcan a una audiencia oral que se fijará dentro de las 96 horas siguiente a la última de las notificaciones (sin contar sábados, domingos, ni días feriados) la notificación podrá hacerse mediante boleta, comunicación telefónica, fax, telegrama, correo electrónico o cualquier medio de comunicación interpersonal, por el órgano jurisdiccional o por el Alguacil, de manera, se precisó después, que sea practicada de la manera más pronta posible, pero tal práctica debe garantizar que la parte que requiere tal 
notificación, tenga cabal conocimiento de la existencia de la misma, de sus fines y de sus consecuencias (sentencia $\mathrm{N}^{\circ} 1501$ de 06-12-2000).

3. En la oportunidad de la audiencia oral y pública (Salvo que excepcionalmente se disponga su reserva) las partes proponen verbalmente sus alegatos y defensas y el tribunal decide si hay lugar a pruebas, en cuyo caso el agraviante producirá las suyas, todo los cual se recogerá en un acta.

4. Una vez concluido el debate oral el tribunal podrá decidir inmediatamente en cuyo caso expone en forma oral los términos del dispositivo del fallo, el cual se publicará dentro de los cinco días siguientes o podrá diferir la audiencia por un máximo de 48 horas por estimar que sea necesaria la presentación o evacuación de alguna prueba o a petición de alguna de las partes o del Ministerio Público.

5. Contra la decisión habrá apelación a un solo efecto dentro de los tres (3) días siguientes y, a falta de recurso, se consultará de conformidad con el artículo 35 de Ley Orgánica de Amparo Sobre los Derechos y Garantías Constitucionales.

6. Cuando el amparo sea contra sentencias se notificará al juez del tribunal correspondiente por un medio escrito que deberá anotarse al expediente de la causa donde se emitió el fallo y al as parte en su domicilio procesal. Deberá acompañarse con copia certificada de la sentencia impugnada o con copia simple, con la carga de producir la copia certificada en la audiencia oral. Las partes en el juicio primigenio podrán hacerse parte hasta dentro de la audiencia pública y los terceros deberán acreditar intereses legítimos y directos ante de la audiencia. La ausencia del juez no comportará aceptación de los hachos incriminados.

\section{REFLEXIONES FINALES}

El precepto dogmático de la Constitución de 1961 contenido en este artículo 49, (actualmente artículo 27 de la Constitución de 1999) sirve de fuente inmediata para fundamentar el amparo constitucional establecido en el Artículo 1 de la Ley Orgánica. En primer lugar, el legislador establece una diferenciación entre la regulación del amparo en general y la garantía de la libertad personal o individual que viene a ser el habeas corpus.

Debe considerarse que en la doctrina, y aún en el texto constitucional, es preciso distinguir entre los derechos consignados en la Constitución y garantías de los mismos, que no son otra cosa que los medios procesales por medio de los cuales es posible su protección y eficacia, y es este sentido el adoptado por la mayoría de la doctrina nacional sobre el Amparo, consagrado en el Artículo 27 de la Constitución Bolivariana de la República de Venezuela (1999).

El amparo constitucional es un mecanismo del cual se dota a los ciudadanos de un país para controlar la constitucionalidad de los actos del poder público y de los demás miembros de la sociedad. Si la Constitución de un país es el instrumento por medio del cual se define el Estado de Derecho, entonces la defensa de ese Estado de 
Derecho es un poder-deber de todos los miembros de la comunidad, y precisamente el amparo es un mecanismo efectivo para que la conducta de todos los miembros de la comunidad y la actividad de todos los órganos del poder público estén apegados a los preceptos que quedaran plasmados en el acto constitutivo de la República.

El amparo constitucional visto desde un enfoque de su eficacia social radica en el hecho de que posee un carácter especial, ya que garantiza los derechos inherentes a la persona y no se considera por tanto, como un control de constitucionalidad ni de legalidad, no regula normas ni leyes, su control va directamente a los derechos fundamentales infringidos; es un medio especial que garantiza los derechos constitucionales y para ser procedente, pero las vías procesales ordinarias que otorga el ordenamiento jurídico venezolano no son las más adecuadas, son insuficientes para evitar el daño causado y no son oportunas en la restitución del derecho.

Desde el punto de vista jurídico, luego de la vigencia de la Constitución Nacional (1999), el Amparo en Venezuela ha tenido sustanciales modificaciones realizadas por la jurisprudencia de la Sala Constitucional del Tribunal Supremo de Justicia, lo que hace necesario una nueva sistematización del Amparo Constitucional y así garantizar una seguridad jurídica mediante la reforma de la Ley Orgánica de Amparo, incorporando los criterios establecidos por la Sala Constitucional concatenados con lo establecido en la Constitución

\section{THE VENEZUELAN SYSTEM OF CONSTITUTIONAL PROTECTION}

\section{Summary}

The nature of protection is enshrined in the Constitution of the Bolivarian Republic of Venezuela as a judicial mechanism ; some authors consider that the protection is also a human right that guarantees the existence of other human rights ; so it is considered a guarantee but actually goes further, because it is seen as a protection system. This study is framed in a research of Constitutional Law, the methodology is based on a literature study documentary- where the main sources of consultation were the Constitution of the Bolivarian Republic of Venezuela and the Organic Law on Protection of Rights and Constitutional Guarantees. The study addresses some basic aspects of the system of constitutional protection and the doctrinal principles that govern it.

Keywords: Law, Constitutional Amparo, Constitution.

\section{BIBLIOGRAFÍA}

ARAGÓN R., Manuel. (1998). Estudios de Derecho Constitucional. Madrid: Centro de Estudios Políticos y Constitucionales.

(2001). Temas básicos de Derecho Constitucional. Tomo III. Tribunal Constitucional y Derechos Fundamentales. Madrid: Gráficas Rogar S.A. 
BADELL, Madrid Rafael (2014) La protección de los intereses colectivos o difusos en Venezuela. Revista Electrónica de Derecho Administrativo Venezolano № 2/2014. (Páginas 34-39)

BELLO LOZANO, H y Bello Lozano, A (1995). Teoría general del proceso. (8va edición). Caracas: Mobil libros.

BELLO TAVARES, Humberto. (2012). Sistema de Amparo (Un enfoque crítico y procesal del Instituto). Ediciones Paredes II. Caracas, Venezuela.

BREWER- CARIAS, Allan (1993). El amparo a los derechos y garantías Constitucionales. (Una aproximación comparativa). Cuadernos de la catedra fundacional Allan R. Brewer-Carias de Derecho Público, №1. Universidad Católica del Táchira. Editorial Jurídica Venezolana.

(1996). Instituciones Políticas y Constitucionales. Tomo VI. La Justicia Constitucional.

CORDÓN MORENO, Faustino. (1979). Anotaciones acerca de la legitimación. Revista de Derecho Procesal Iberoamericana. Madrid. Número 2, año 1979, pp.305-339.

CONSTITUCIÓN DE LA REPÚBLICA DE VENEZUELA (1961). Gaceta Oficial de la República de Venezuela número 3.251, (extraordinaria) Septiembre 12, 1983.

CONSTITUCIÓN DE LA REPÚBLICA BOLIVARIANA DE VENEZUELA (1999). Gaceta Oficial de la República Bolivariana de Venezuela número 5.453. (extraordinaria). Marzo 24, 2000.

CHAVERO G, Rafael (2001). El nuevo régimen de amparo constitucional en Venezuela. Caracas: Editorial Sherwood.

DÁVILA A, Jesús. (2001). El derecho a la información y la libertad de expresión en Venezuela. Revista de Derecho Constitucional número 5 (julio- diciembre 2001). Caracas: Editorial Sherwood.

D. G.T. WILLIAMS, Administrative Law in England: The Emergence of a New Remedy, 27 Wm. \& Mary L. Rev. 715 (1986), http://scholarship.law.wm.edu/wmlr/vol27/iss4/7

HOYOS, A. (1989). La Interpretación Constitucional. Santa Fé de Bogotá: Editorial Temis.

KELSEN, H (s/f) Teoría pura del Derecho. Argentina: Editorial Universitaria Buenos Aires.

KIRIAKIDIS L., Jorge C. (2012). El Amparo Constitucional Venezolano: mitos y realidades. Editorial Jurídica Venezolana. Colección Justicia № 1.

LEY ORGÁNICA DE AMPARO SOBRE DERECHOS Y GARANTÍAS CONSTITUCIONALES (1988) Gaceta Oficial de la República de Venezuela №34.060 de fecha 27 de septiembre de 1988.

LEY ORGÁNICA DEL TRIBUNAL SUPREMO DE JUSTICIA (2004) Gaceta Oficial de la República Bolivariana de Venezuela N 37.942 de fecha 20 de mayo de 2004.

LINARES B., Gustavo J. (1993). El Proceso de Amparo en Venezuela. Editorial Jurídica Venezolana. Caracas. (1999). El Proceso de Amparo. Tesis Doctoral. Universidad Central de Venezuela. Publicado en la Revista de la Facultad de Ciencias Jurídicas y Políticas No113. Caracas. Venezuela. 
MAGO BENDAHAN, Oscar. (1998). El Amparo Constitucional Civil (un enfoque no conformista). Tesis Doctoral Magna Cum Laude. Universidad Central de Venezuela. Editorial: Constitución Activa, breviarios del Nuevo Derecho.

MONTOYA, Cesar A. (2013). El Amparo Constitucional. Ediciones Liber. Venezuela.

PLAZ, René; Duque, Román; Romero-Muci, Humberto. (1989). El Recurso de Amparo en la Legislación Venezolana. Biblioteca de la Academia de Ciencias Políticas y Sociales. Serie Foros No 2. Caracas.

RENGEL ROMBERG, A. (1995). Tratado de derecho procesal civil venezolano según el nuevo código de 1987. (Volumen II). Caracas: Editorial Arte.

RONDÓN DE SANSÓ, Hildegard. (1994). La Acción de Amparo contra los Poderes Públicos. Editorial Arte. Caracas, Venezuela.

TRIBUNAL SUPREMO DE JUSTICIA $(\mathrm{s} / \mathrm{f})$. Sentencias de la Sala Constitucional. http://www.tsj.gov.ve/decisiones/scon/Febrero/279-190202-02-0093\%20.htm

VILLEGAS M, José Luis. (1999). La protección jurisdiccional de los intereses difusos y colectivos. Cuadernos de la catedra fundacional Allan R. Brewer-Carias de Derecho Público, No6. Universidad Católica del Táchira. Editorial Jurídica Venezolana.

Trabalho enviado em 29 de junho de 2015.

Aceito em 22 de setembro de 2015. 